\title{
Classification, Identification, and Manipulation of Relevant Factors for Adaptation and Behavioural Adjustment from a Psychological Point of View
}

\author{
Gerardo Ortiz \\ Centro de Estudios e Investigaciones en Comportamiento, Universidad de Guadalajara, Guadalajara, México \\ Email: oruga@cencar.udg.mx
}

Received 3 May 2014; revised 1 June 2014; accepted 27 June 2014

Copyright (C) 2014 by author and Scientific Research Publishing Inc. This work is licensed under the Creative Commons Attribution International License (CC BY). http://creativecommons.org/licenses/by/4.0/ c) (i) Open Access

\begin{abstract}
Generally, the study of animal welfare is based on the identification and promotion of speciestypical behaviors of the individual or target group. The adjustment to new conditions (i.e. captivity) is easier for some species, while for others it may be very difficult or even impossible. The adjustment to captive conditions is a basic element for the development of conservation strategies (i.e. translocation, introduction, and reintroduction) and can be measured by different variables related to an animal's psychological well-being. From a psychological point of view, we assume that organisms can adjust their behavior in correspondence to changes in their environment, adjustment that is enabled by an ecological contact medium (e.g. Ribes, 2007; Ribes \& Perez-Almonacid, 2011). Under this assumption, we propose a methodology that allows the classification, identification and manipulation of relevant factors for an individual's adjustment to different conditions (i.e. freedom and captivity) and a more rational handling of organisms and their specific life condition. The main elements of this methodology are: 1) adaptive and survival circumstances; 2) description of ecological milieu; 3) interactive processes (i.e. intra-individual, inter-individual, and inter-individual dependence); and 4) interaction-situation relationship.
\end{abstract}

\section{Keywords}

Psychological Adjustment, Adaptation, Conservation Strategies, Captivity, Wild 


\section{Behavior from a Psychological Point of View}

In the study of animal behaviour in conditions of freedom or captivity, one of the departure points (and, sometimes, the main objective) is the identification of specific behavioural patterns, particularly the role of trigger or sign stimuli (e.g. Fachinnetti \& Reboreda, 2013; Hinde, 1977; Koloff \& Mennill, 2013; Lopez-Luján \& Ramirez, 1993; Maier, 1998; Masatomi, 1983; Rushen, 1972; Tinbergen, 1981; Zipser, Kaiser, \& Sachser, 2013). In this sense, Barnett (1963) suggested that knowledge of these specific patterns would allow us to predict the behaviour of any individual of any species, without knowing its history (e.g. Deschner, Heistermann, Hodges, \& Boesch, 2004; Himmler, Stryjek, Modlinska, Derksen, Pisula, \& Pellis, 2013; Ishii \& Hasgeawa, 2013).

To speak of specific patterns might suggest inter- and intra-individual behavioural constancy, but it is usually accepted that different environmental conditions affect and modify such patterns (i.e. Tanaka, Mori, \& Hasegawa, 2001, McCowan \& Rommeck, 2006). This acceptance, however, is not necessarily reflected in practice (i.e. Blanchard, Blanchard, Cholvanich, \& Mayer, 1989; Pellis, 1989; Morgan y Tromborg, 2007; USDA, 2010; Wemelsfelder, 1990). Several authors have proposed that organisms' behaviour, both phylogenetic and ontogenetic, is controlled by the environmental stimuli that surround them, which is part of the so-called proximal causes in ethology (i.e. Honig, 1987; Skinner, 1975, 1977; Tinbergen, 1981). Hinde (1977) assumed that such control could be exerted through the trigger of behavioural patterns (i.e. a liberating function), the direction of the response (i.e. an orientation function) or behavioural halting (i.e. a consummatory function).

When an organism behaves in a specific situation, it is responding to elements and particular events that compose that situation. Such elements have both a physical-chemical nature (i.e. the environmental temperature or the scents of certain types of plants and animals), and a quasi-conventional nature as in the formation and dynamics of the social group in which it is immersed. Thus, one can say that the situation is composed of the different resources necessary to cover the requirements of nutrition and protection as well as of intra and interspecific interactions (e.g. Rodríguez-Luna, 1998). Amongst the elements that could be part of the description of the situation of the subject, group or species under study are other individuals of the social group (i.e. characterristics such as the size of the group, the demographic distribution, and an established hierarchy), other individuals and/or social groups of the same species with which they could make contact, as well as groups and/or individuals of other species with which they could compete or have sympatric relationships, diverse characteristics of the distribution of trees and plants which serve as food and/or refuge.

According to Kantor (1924), human and animal behaviour can be approached from different points of view such as biology, anthropology and literature. From a psychological point of view, behaviour can be identified as the adjustment that results from an interaction with the changing conditions of the surrounding environment. This adjustment must have certain characteristics to be considered as a psychological adjustment, including variability, differentiation, modifiability, integration, delay and inhibition of reaction. An organism, therefore, can have different responses to the same stimulus (i.e. variability of reaction), as in the case of an individual who displays different behaviors at the time of the search, selection and feed consumption, under similar conditions. This variable nature of the psychological response allows the organism to increase its efficiency in adjustment to its environment. The possibility of responding differentially to different stimuli (i.e. differentiation of reaction) is the basis of the variability of behaviour. The psychological organism is able to discriminate between objects that comprise its surrounding environment, responding differentially to different stimuli in the same context or to the same stimuli in different contexts. Thus, we can observe an individual that displays some kind of behavioural pattern facing a particular stimulus set, but emitting another sort of behaviour if one of the stimuli changes, altering the stimulus set.

Once an object produces some effect upon an organism, this effect usually persists. If we agree on the variability and differentiation of reaction, we can suppose that behaviour can be modified with direct reference to previous contacts that the organism has had with those stimuli and to present variations in the environment (i.e. modifiability of reaction). However, organisms not only behave differentially to objects with the later reaction modification but also add or integrate these responses in more and more complex reactions (i.e. integration of reaction). Thus, the psychological organism can develop complex reactions that can be identified as the combination of simpler reactions. A basic characteristic of the so-called psychological behaviour is the fact that objects can produce effects upon organisms, long after those objects have ceased to be in direct contact with the organism (i.e. delay of reaction). This characteristic implies some degree of an organism's independence of its stimulating surroundings. But not only can the organism delay its reaction to the present stimuli, but also it can 
completely inhibit its responses and perform others instead (i.e. inhibition of reaction). In the same token, some authors (i.e. Kantor, 1924; Ribes, 2007; Ribes \& Pérez-Almonacid, 2011) suggest that the type of possible relationships between an organism and its environment are supported by a particular contact medium (i.e. pysicochemical, ecological, conventional). In addition to the physicochemical and organismic properties, ecological relational properties (i.e. number of objects, individuals, species, locations, relationships between them) are those that enable and regulate the occurrence and distribution of behavioral patterns, whose ultimate function is individual adjustment.

Each species and each individual of the species, by means of its psychological characteristics, keep a singular relation with the environment and other species. Thus, each species (anatomically, physiologically, and behaviourally adapted to its surroundings), develops behavioural modifications not only for its survival (Maier, 1998), but also for the sustainable maintenance of the dynamics of the ecosystem of which it is a part. Although the individuals belonging to a particular species share anatomical-physiological characteristics-and for that reason they are identified as members of a species - in the course of the ontogeny, and due to different conditions and situations that an individual or group of individuals faces, the behaviour of the members of the species may eventually differ, sometimes diametrically (e.g. Hewitson, Dumont, \& Gordon, 2005; Gyssels \& Stoks, 2006; Plesner-Jensen, Gray, \& Hurst, 2005; Stenberg \& Persson, 2005).

\section{Captivity Conditions, Psychological Adjustment and Captivity Resistance}

Although all the parts of any organism are adapted to their life conditions, the modification of the individual behaviour, like mechanisms of adaptation or adjustment to the changing environmental conditions, and even of the anatomy of the species, is usually a function of the stimulatory differences that the organisms face (e.g. Lorenz, 1979; Riesch, Schlupp, \& Plath, 2006; Taru, Kanda, \& Sunobe, 2002; Vicente \& Paulo, 1989). This suggests that if one of the elements that constitute the situation (i.e. environment in which the organisms are inserted) is modified, the organism-environment interaction will be modified (Kantor, 1924). For example, Vicente and Paulo (1989) studied the behavioural, ecological and morphological adaptations of a species of small lizards (Lacereta lepida) to their particular environment. They observed different behavioural patterns related to environmental characteristics such as the ecological milieu, the amount, distribution and type of food, as well as the population density.

In addition, Chapman (1988) showed a relevant influence of season, the abundance or lack of food and the type of vegetation on the pattern of space use in howling monkeys (Alouatta palliata), white face capuchins (Cebus capucinus) and spider monkeys (Ateles geoffroyi), as well as the vervet monkey (Cercopithecus aethiops pygerythrus). It has been observed that diet varies according to the environmental conditions, and the activity patterns of Crested black macaque Macaca nigra (i.e. to travel, to feed themselves, to rest) change depending on the season of the year (e.g. Cawthon-Lang, 2006). In this sense, the environmental factors that have been said to have a stronger effect on social organization are: 1) wealth and distribution of the nutritional resources and; 2) the presence of predators and/or prey (e.g. Rodríguez-Luna, 1998; Takahashi, Sato, Nishikawa, Watanuki, \& Naito, 2004).

In the literature it has been identified an ample repertoire of activities that different species do and the events that occur before these activities (e.g. Bolin, 1981; Bosch, Márquez, \& Boyero, 2003; Carrera-Sánchez, 1994; Chapman, 1988; Yabuta, 2000; Jaman \& Huffman, 2008; Ortiz \& Reyes-Domínguez, 2011; Ortiz, 2012). By the same characteristics of this listing, sometimes it is difficult, if not impossible, to identify those elements relevant to the emission of these activities and to the capacity for adaptation of these different species, beyond the possible liberating stimuli or signs of the behaviours under study. This problem is of great relevance within the area of species conservation.

Because of the deterioration of natural resources, the basis of different conservation tactics is captivity, which can last from a few days when we talk about translocation, to several years when we talk about introduction (e.g. Rodríguez-Luna et al. 1993). In captivity, the conditions under which the individuals or groups of different species live differ considerably from those who live "naturally". We can see modifications in the space they live in and in the population density (i.e. territory is delimited, social groups are more or less stable and structured, generally there are no predators to avoid, while there are few_if any — possibilities of intra and interspecific competition), as well as in nutritional aspects and in the search for food (i.e. water and food are given at specific times and places, with all necessary nutrients provided in different food sources) (e.g. Caldecott, 1986; Boinski, 
1988; Boccia \& Hijazi, 1998; Jaman, Huffman, \& Takemoto, 2010; Jaman \& Huffman, 2011; Jaman \& Huffman, 2013).

There are species that adapt to captive conditions quite easily (i.e. Cercopithecus aethiops pygerythrus or vervet monkey), but there are others that cannot be kept under this condition for very long (i.e. Alouatta palliata mexicana or howling monkey). Problems related to feeding are commonly considered to be one of the principal factors responsible for this (Serio-Silva, 2000). This problem can be called "captivity resistance" and implies the difficulty of individuals to survive under these conditions. The close relationship between the concept of "captivity resistance" and the difficulty that different species have to adjust to drastic and sudden disturbances in their habitat appear evident. This ability to adjust to captive conditions is an element of vital importance for the adequate development of common animal conservation strategies (i.e. translocation, introduction and reintroduction). From a psychological point of view, one of the first steps to study the adjustive ability of a species (specifically the so-called "captivity resistance") is the identification of the stimuli and environmental events that are relevant to different species and the effect that their modification would have on individual behaviour. This assertion comes from the following assumptions:

1) The environment can be analyzed as a series of stimuli;

2) The organism must be studied as a being that behaves (interacts with its environment) and not only as a being that perceives its environment (e.g. Gibson, 1986);

3) If one of the interaction elements is changed (organism and/or environment) the interaction changes (the manner in which the organism behaves);

4) Some species can adapt to changes in their environment quicker than others.

Therefore, it is important to create a general methodology that allows us to categorize and manipulate in a simple and general way those environmental elements relevant to behaviour, independently of the species under study. To accomplish this task, it is proposed that the following particular objectives be applied, regardless of life condition (i.e. wild, captivity) of the individual or group target:

a) Description of how the ecological environment is structured;

b) Identification and classification of the adaptive and survival circumstances, interactive processes and interaction-situation relationships implied;

c) Use of adequate observation techniques for each case;

d) Evaluation of the relevant variables for adaptation to living conditions;

e) Elaboration of experimental or quasi-experimental techniques for the manipulation of the relevant variables;

f) Manipulation of the variables that have been proven to be theoretically or empirically (i.e. with systematic observations) relevant.

\section{The Analytic Proposal: Description of the Ecological Milieu}

In this paper, we will proceed with objectives $a$ and $b$. A schematic representation of the described system is presented in Figure 1.

We can analyze and describe the ecological milieu using three general categories:

1) Geophysical factors: physical-chemical elements of the environment such as scents, colours, or flavours;

2) Geo-ecological factors: geographical distribution of elements such as type of land or enclosure, location and size of feeding, resting and protective zones (shelters);

3) Intra-interspecific interaction factors: presence or absence of other species or individuals; for example, we can describe the number of individuals/groups of other species with sympatric or competitive relationships with our target group or subject.

An adaptive and survival circumstance is defined as the manner/situation in which an individual-group-species interacts with another individual-group-species increasing or decreasing, ultimately, their reproductive aptitude (basis of evolution by natural selection). In the behavioural study of animals in their natural environments, different adaptive and survival circumstances have been considered. For example, Klopfer (1974) considers as relevant activities, among others, the social organization (i.e. territoriality, individual distance, dominance relationships, leadership, parental care), and mutual stimulation (i.e. help, grooming others, reciprocal visual and auditory exchanges, observational learning). Maier (1998) suggests that the relevant activities are feeding (i.e. 


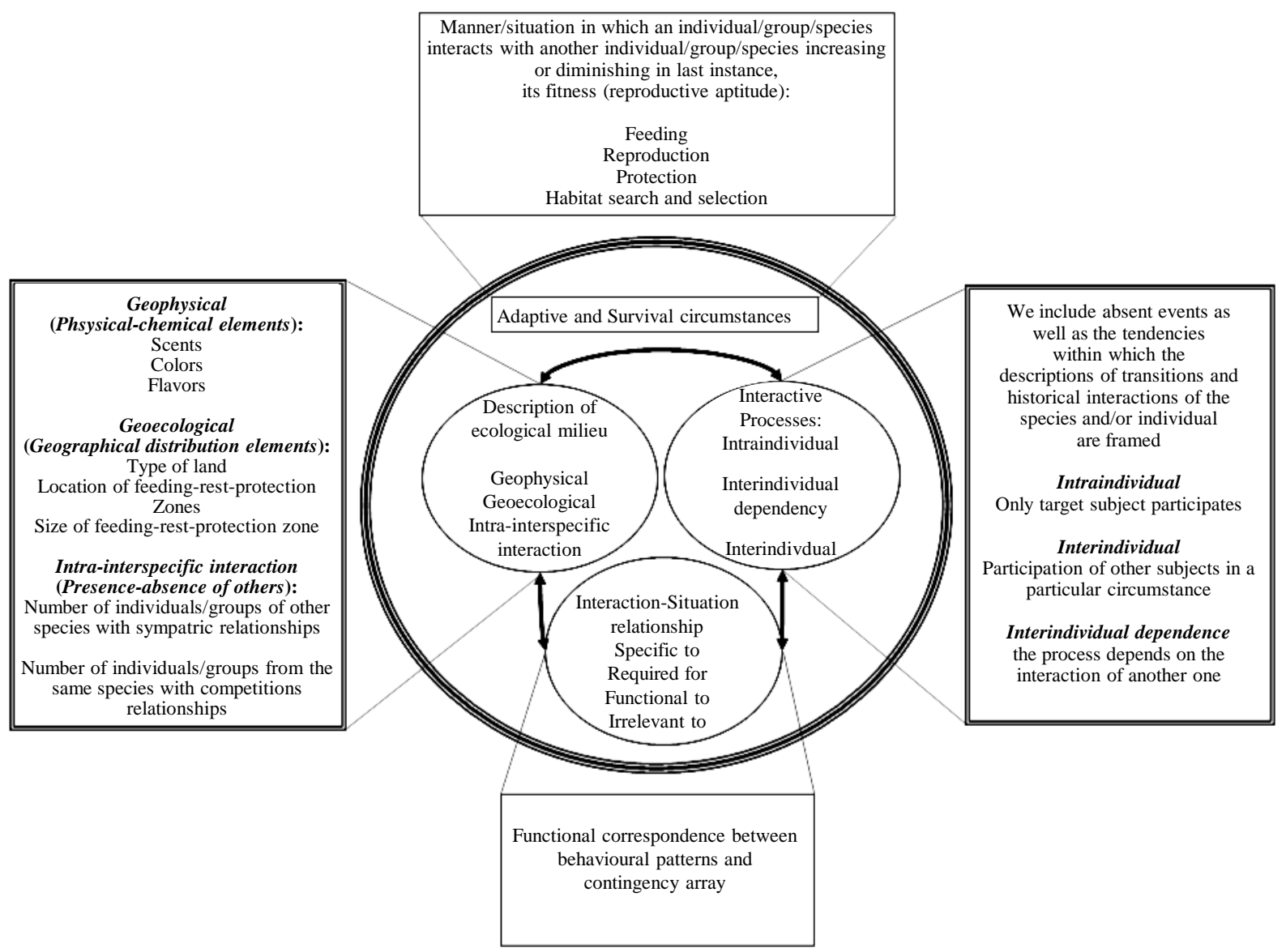

Figure 1. Factors/elements of the ecological milieu, relevant in the identification of the stimuli and environmental events that affect animal behavior.

intra and interspecific competition), defense against predation (i.e. techniques and strategies such as detection, confusion effect, dilution effect, resource unity, escape, defensive aggression, advertising strategies), attraction, courtship and mating, parental care, migration and navigation, emigration, habitat selection and regulation of population, intraspecific social behaviour (i.e. cooperation, communication, competition, aggression, pacification) and interspecific social behaviour (i.e. parasitism, commensalism, and mutualism).

In general, we can observe that the main criterion for the acceptance of an event as relevant for a particular circumstance is its constitution as a discrete moment of temporal-spatial occurrence. For example, that a certain organism presents a determined coloration during a sexual activity period or to show its teeth as part of a ritualized aggression act. This fact has as a consequence, the logic exclusion of any element that does not constitute a discrete event (i.e. any type of trends shown by the studied organism) or elements whose causal sequence is not yet proven (i.e. occurrence of events separated in time from the target one).

In an attempt to include contextual variables, absent events as well as trends in the present analysis, which frames the descriptions of historical transitions and interactions of the species and/or individual, we can describe the different adaptive and survival circumstances based on three different interactive processes: inter-individual, intra-individual and inter-individual dependence. The difference between inter- and intra-individual processes lies in the participation of different subjects in relation to the target individual in a particular adaptive circumstance. An inter-individual dependence process constitutes a different process because of its subordination to the interaction with other individuals; without those others, the probability of adjustment and survival decreases considerably, so much that without the presence of the "other", the individual could die. It should be mentioned that this process is not restricted to social species because the relevant dependence can also be given from the presence, or any behaviour, of individuals of other species.

An example of the inter-individual dependence process is parental care, which occurs independently of how it 
is expressed in each species. The occurrence of parental care is of vital importance for the infant's survival, and in mammalian species, for example, it often represents the unique opportunity for infants to learn specific forms of interaction under particular environmental conditions.

A classification based on the aforementioned criteria would allow the reconceptualization of the organisms' activity, because the same adaptive and survival circumstance may be analyzed by the different processes implied. An example of this can be taken from one of the adaptive circumstances that have been widely studied in the literature of animal behaviour, the search for food (also known as foraging). The search for food can be defined as the accumulation of food, including food gathering (i.e. presented in a food box) or to gather food items to which they have no direct access (i.e. presented in a food dispenser). It does not include feeding behaviour, such as putting food in the mouth, storing food in the cheek pouches, taking food from the cheek pouches or chewing and swallowing the food.

The search for food, as an intra-individual process consists of the search, identification, selection, and food gathering by one individual, independently of the presence/absence of other organisms. However, it may also be considered an inter-individual process because the actions that comprise it can be modified or presented with different rates depending on the presence of other individuals of the same or different species, irrespective of the "target" subject belonging to a species considered social. Finally, the search for food as a process of inter-individual dependence would identify the need for the presence of another organism so that the "target" individual can develop the behaviours related to food recollection. For instance, it is possible to find in a particular species that the presence of, and interaction with, other organisms can be a condition sine qua non of foraging, parasitism being the extreme case.

Finally, we need to analyze specific interactions in terms of their relationship with the situation or contingency array. A contingency array can be defined as a group of elements, factors and/or variables that keep particular interactive relations among themselves, structuring an interaction network. The special direction of those relations shapes a particular situation. In this sense, different situations can be composed of the same kind of elements and variables, but they will differ from each other in the particular relationship between their elements. According to Torres (2005), we can identify at least four kinds of functional correspondence between behavioural patterns and the contingency array: 1) interaction or behaviour specific to the contingency, 2) interaction or behaviour required by the contingency, 3) interaction or behaviour functional to the contingency, and 4) interaction or behaviour irrelevant to the contingency array.

According to this view, behavioural patterns linked to foraging in a specific situation can be qualified depending on their functional correspondence with the contingency array. Thus, for example, a behaviour such as to clap just before food is delivered can be identified as irrelevant to or required by the situation, depending on the necessity of this behaviour to obtain food.

\section{Conclusions: Some Thoughts about Captivity, Behavioral Enrichment and Animal Welfare}

The identification of the interactive processes implied in adaptive circumstances, the description of the ecological milieu, and the functional correspondence between behavioural-situations will allow a more precise identification and manipulation of the relevant factors in the adaptation of each species. At the same time, this allows a more rational management of organisms and their life conditions. As a result, it may be possible to reduce undesirable effects such as the "resistance to captivity", by manipulating those factors that could entail risk for different individuals/species. At the same time, it could be possible to predict, with a high degree of certainty, the threat of extinction that any species could face if the identified factors are not modified.

For example, one aspect that has been considered relevant to captivity is the fact that, under the conditions of confinement, the captive species usually lives in small spaces with routine regimes of feeding and life that do not allow the emission of varied behavioural patterns (e.g. Guerrero, 1997); this characteristic entails the emission of stereotyped patterns that can end up in the deterioration of health and, therefore, the maladaptation of the organism. The general mission of enrichment strategies is to promote the emission of species' typical behavioural patterns (e.g. Guerrero, 1997; Markowitz, 1978; Snowdon, 1991) that in natural conditions have an adaptive function. In this general strategy, it is proposed that in order to maintain confinement conditions as natural as possible, it is necessary to include objects the organism can interact with and manipulate, and promote intraspecific social interaction allowing for the psychological well-being of captive individuals. 
In agreement with the National Research Council committees (1998) the manner in which an animal adapts to environmental changes or brief environmental disturbances can provide information about its psychological state. Therefore, a particular type of disturbance is necessary to evaluate the adjustment of the given reaction, as well as the time that the animal takes to adjust to the situation (i.e. temporary or new). In order to evaluate the psychological well-being of the non-human animals, we need to take into consideration: 1) the ability of the animal to handle, in an effective way, daily changes in its physical and social atmosphere, in reference to its own necessities, 2) the ability of the animal to involve itself in typical beneficial activities of its species, 3) the absence of maladaptive or pathological behaviours that can produce any kind of injury or other undesirable consequences, 4) the presence of a balanced temperament shown as an appropriate balance of aggression-passivity. In this sense, the psychological well-being has been defined as the absence of chronic signs of pain indicated by the presence of vocalizations, facial expressions, physiological reactions like accelerated breathing, excessive cardiac response and abnormal hormonal levels (Commission on Life Sciences, 1998).

Diverse proposals have been made to define psychological well-being and environmental enrichment, assuming that behaviours that the animals develop in their natural habitat and those developed in captivity are, or should be, the same. Nevertheless, if the behaviour of the species is determined by the elements and its relationships to the environment in which it is developed, it would be obvious that expressed behaviour in both conditions (i.e. freedom and captivity) can and will be different because the elements and interactions that comprise the "natural" environment are not the same as those that comprise the environment in captivity. Thus, in order to modify those potentially harmful behaviours, it seems necessary to identify the relevant elements of the interaction between the organism, its living context, as well as its particular behavioural patterns (stereotyped or not), through the creation of programs that allow the emission of a greater (i.e. quantitatively and qualitatively) behavioural diversity.

In general, enrichment strategies seek to encourage the so-called social cohesion as well as species specific behaviour, in order to "... put captive animals in a position in which they can learn to actively control and explore some aspect of their environment" (Swaisgood and Shepherdson, 2005: p. 501). They often focus on alimentary or playing behaviours because in captivity there are very few situations/opportunities to express any other behaviour (e.g. Fernández \& Timberlake, 2006; Marashi, Barnekow, \& Sachser, 2004), and are programmed under the assumption that a change in the location of the delivery of food, the increase in the difficulty of access to it, the addition of "live prey" as treats (i.e. different types of insects) or the presence of "novel" objects (i.e. balls, coconuts, different kind of toys) is sufficient to promote both behavioural variability as well as species' typical patterns. Nevertheless, we face at least two questions: 1) given the conditions of captivity, is it feasible and, more importantly, desirable that the individuals emit specific typical patterns like those they present/display in wild conditions? and 2) Does the variability by itself be an efficient psychological well-being indicator?

Some considerations related to the first question were previously made in the present work and the answer depends on the objective of holding animals in captivity (i.e. exhibition like in traditional Zoo's, quarantine for later liberation, breeding for liberation). With respect to the second question, the answer also depends on the objective of the confinement, but it tends to be that variability by itself is not important because, as it has already been established, psychological behaviour is an adjustment of the individual to its environment. For that reason, behaviours that should be promoted as well as those desirable variations must be related to pertinent criteria to the situation in which the organism is found.

In this sense, the proposal made here can allow us to identify aspects related to the expressed behaviour (i.e. its morphology and function), the situation in which it appears (i.e. geophysical, geoecological and interaction characteristics) as well as the relationship between behaviour and adjustment criteria in a specific situation. Our methodology also permits us to identify a stereotypic behaviour that could be pertinent or required in a determined situation, composed by certain elements and characteristics. The identification of those elements will allow us to propose some changes, like adding or withdrawing objects, conspecific individuals, etc., in a quicker and more effective way.

\section{References}

Barnett, S. A. (1963) A Study in Behaviour. London: Methuen and Co.

Blanchard, D. C., Blanchard, R. J., Cholvanich, P., \& Mayer, S. I. (1989). Offensive Behavior as a Prototype for Ethoexperimental Analysis. In: R. J. Blanchard, P. F. Brain, D. C. Blanchard, \& S. Parmigiani (Eds.), Ethoexperimental Ap- 
proaches to the Study of Behavior (pp. 338-360). Dordrecht, Netherlands: Kluwer Academic.

Boccia, M. L., \& Hijazi, A. S. (1998). A Foraging Task Reduces Agonistic and Stereotypic Behaviors in Pigtail Macaque Social Groups. Laboratory Primate Newsletter, 37, 1-4.

Boinski, S. (1988). Sex Differences in the Foraging Behavior of Squirrel Monkeys in a Seasonal Habitat. Behavioral Ecology and Sociobiology, 23, 177-186.

Bolin, I. (1981). Male Parental Behavior in Black Howler Monkeys (Alouatta palliata pigra) in Belize and Guatemala. Primates, 22, 349-360. http://dx.doi.org/10.1007/BF02381575

Bosch, J., Márquez, R., \& Boyero, L. (2003). Behavioural Patterns, Preference, and Motivation of Female Midwife Toads during Phonotaxis Tests. Journal of Ethology, 21, 61-66.

Caldecott, J. O. (1986). An Ecological and Behavioural Study of the Pig-Tailed Macaque. Comparative Physiological Adaptation. Contributions to Primatology Vol. 21, Basel: Karger.

Carrera-Sánchez, E. (1994). Desripción del comportamiento de un grupo de mono aullador. La Ciencia y el Hombre, 18, 127-149.

Cawthon-Lang, K. A. (2006). Primate Factsheets: Crested black macaque (Macaca nigra) Taxonomy, Morphology, \& Ecology. Accessed 2006 October 25. http://pin.primate.wisc.edu/factsheets/entry/crested_black_macaque/taxon

Chapman, C. A. (1988). Patterns of Foraging and Range Use by Three Species of Neotropical Primates, Primates, 29, 177194. http://dx.doi.org/10.1007/BF02381121

Commission on Life Sciences (1998). The Psychological Well-Being of Nonhuman Primates. Washington DC: National Academic Press.

Deschner, T., Heistermann, M., Hodges, K., \& Boesch, C. (2004). Female Sexual Swelling Size, Timing of Ovulation, and Male Behavior in Wild West African Chimpanzees. Hormones and Behavior, 46, 204-215.

http://dx.doi.org/10.1016/j.yhbeh.2004.03.013

Facchinetti, C., \& Reboreda, J. C. (2013). Female Tawny-Bellied Seedeaters Do Not Prefer More Colorful Males in Choice Experiments. Journal of Ethology, 31, 233-238. http://dx.doi.org/10.1007/s10164-013-0371-3

Fernández, E. J., \& Timberlake, W. (2006). The Effects of Foraging Devices as Enrichment in Captive Walruses (Odebenus Rosemarus). 32nd Annual ABA Convention, Atlanta, GA, 26-30 May 2006.

Gibson, J. J. (1986). The Ecological Approach to Visual Perception. Mahwah, NJ: Lawrence Erlbaum.

Guerrero, D. (1997). Enrichment 101: A Basic Overview. http://www.arkanimals.com/E/Enrich101.html

Gyssels, F., \& Stoks, R. (2006). Behavioral Responses to Fish Kairomones and Autotomy in a Damselfly. Journal of Ethology, 24, 79-83. http://dx.doi.org/10.1007/s10164-005-0165-3

Hauver, S., Hirsch, B. T., Prange, S., Dubach, J., \& Gehrt, S. D. (2013). Age, but Not Sex or Genetic Relatedness, Shapes Raccoon Dominance Patterns. Ethology, 119, 769-778. http://dx.doi.org/10.1111/eth.12118

Hewitson, L., Dumont, B., \& Gordon, I. J. (2005). Response of Foraging Sheep to Variability in the Spatial Distribution of Resources. Animal Behaviour, 69, 1069-1076.

http://dx.doi.org/10.1016/j.anbehav.2004.09.004

Himmler, B. T., Stryjek, R., Modlinska, K., Derksen, S. M., Pisula, W., \& Pellis, S. M. (2013). How Domestication Modulates Play Behavior: A Comparative Analysis between Wild Rats and a Laboratory Strain of Rattus norvegicus. Journal of Comparative Psychology, 127, 453-464. http://dx.doi.org/10.1037/a0032187

Hinde, R. A. (1977). Introducción a la etología para psicólogos. Buenos Aires: Nueva Visión.

Honig, W. K. (1987). Local Cues and Distal Arrays in the Control of Spatial Behavior. In P. Ellen, \& C. Thinus-Blanc (Eds.), Cognitive Processes and Spatial Orientation in Animal and Man (pp. 55-72). Leiden: Martinus Nijhoff Publishers.

Ishii, Y., \& Hasgeawa, E. (2013). The Mechanism Underlying the Regulation of Work-Related Behaviors in the Monomorphic Ant. Journal of Ethology, 31, 61-69. http://dx.doi.org/10.1007/s10164-012-0349-6

Jaman, M. F., \& Huffman, M. A. (2008). Enclosure Environment Affects the Activity Budgets of Captive Japanese Macaques (Macaca fuscata). American Journal of Primatology, 70, 1133-1144. http://dx.doi.org/10.1002/ajp.20612

Jaman, M. F., \& Huffman, M. A. (2011). Age Class Differences in the Feeding Behavior of Captive Japanese Macaques (Macaca fuscataia) in the Forested and Nonvegetated Enclosure Groups. Zoo Biology, 30, 260-274. http://dx.doi.org/10.1002/zoo.20324

Jaman, M. F., \& Huffman, M. A. (2013). The Effect of Urban and Rural Habitats and Resource Type on Activity Budgets of Commensal Rhesus Macaques (Macaca mulatta) in Bangladesh. Primates, 54, 49-59.

http://dx.doi.org/10.1007/s10329-012-0330-6 
Jaman, M. F., Huffman, M. A., \& Takemoto, H. (2010). The Foraging Behavior of Japanese Macaques Macaca fuscata in a Forested Enclosure: Effects of Nutrient Composition, Energy and Its Seasonal Variation on the Consumption of Natural Plant Foods. Current Zoology, 56, 198-208.

Kantor, J. R. (1924). Principles of Psychology. Vol. 1, Chicago, IL: The Principia Press.

Klopfer, P. H. (1974). An Introduction to Animal Behavior. Upper Saddle River, NJ: Prentice-Hall.

Koloff, J., \& Mennill, D. J. (2013). The Responses of Duetting Antbirds to Stereo Duet Playback Provide Support for the Joint Territory Defence Hypothesis. Ethology, 119, 462-471. http://dx.doi.org/10.1111/eth.12084

López-Luján, A., \& Ramírez, M. I. (1993). Estudio conductual de la competencia por la comida en macacos cola de muñón (Macaca arctoides) en cautiverio. In A. Estrada, E. Rodríguez-Luna, R. López-Wilchis, \& R. Coates-Estrada (Eds.), Estudios primatológicos en México (pp. 241-254). Xalapa: Biblioteca Universidad Veracruzana.

Lorenz, K. (1979). Evolution et modification du comportement. Paris: Petit Bilbliothèque Payot.

Maier, R. (1998). Comparative Animal Behavior: An Evolutionary and Ecological Approach. Boston, MA: Allyn \& Bacon.

Marashi, V., Barnekow, A., \& Sachser, N. (2004). Effects of Environmental Enrichment on Males of a Docile Inbred Strain of Mice. Physiology \& Behavior, 82, 765-776. http://dx.doi.org/10.1016/j.physbeh.2004.05.009

Markowitz, H. (1978). Engineering Environments for Behavioral Opportunities in the Zoo. The Behavior Analyst, 1, 34-47.

Masatomi, H. (1983). Some Observations on Mating Behaviour of Several Cranes in Captivity. Journal of Ethology, 1, 62-69. http://dx.doi.org/10.1007/BF02347831

McCowan, B., \& Rommeck, I. (2006). Bioacoustic Monitoring of Aggression in Group-Housed Rhesus Macaques. Journal of Applied Animal Welfare Science, 9, 261-268. http://dx.doi.org/10.1207/s15327604jaws0904_1

Morgan, K. N., \& Tromborg, C. T. (2007). Sources of Stress in Captivity. Applied Animal Behaviour Science, 102, $262-302$. http://dx.doi.org/10.1016/j.applanim.2006.05.032

National Research Council Committees (1998). The Psychological Well-Being of Non Human Primates. Washington DC: National Academy Press.

Ortiz, G. (2012). Afluencia de visitantes, zona del encierro y emisión de conductas afiliativas y agonísticas en monos vervet (Cercopithecus aethiops pygerythrus) en cautiverio en el zoológico. IPyE: Psicología y Educación, 6, 56-71.

Ortiz, G., \& Reyes-Dominguez, A. (2011). Distribución espacio temporal de patrones conductuales de monos araña (Ateles geoffroyi yucatanensis) en cautiverio. In L. Gama-Capillo, G. Pozo-Montuy, W. M. Contreras-Sánchez, \& S. T. ArriagaWeiss (Eds.), Perspectivas en Primatologia Mexicana (pp. 145-164). Villahermosa: Universidad Juarez Autonoma de Tabasco, Colección Jose Narciso Rovirosa.

Pellis, S. M. (1989). Fighting: The Problem of Selecting Appropriate Behavior Patterns. In R. J. Blanchard, P. F. Brain, D. C. Blanchard, \& S. Parmigiani (Eds.), Ethoexperimental Approaches to the Study of Behaviour (pp. 361-374). Dordrecht, Netherlands: Kluwer Academic Publishers.

Plesner-Jensen, S., Gray, S. J., \& Hurst, J. L. (2005). Excluding Neighbours from Territories: Effects of Habitat Structure and Resource Distribution. Animal Behaviour, 68, 785-795. http://dx.doi.org/10.1016/j.anbehav.2004.07.008

Ribes, E. (2007). Estados y límites del campo, medios de contacto y análisis molar del comportamiento: Reflexiones teóricas. Acta Comportamentalia, 15, 229-259.

Ribes, E., \& Pérez-Almonacid, R. (2011). La función lógica del concepto de medio de contacto. Acta Comportamentalia, 20, 235-249.

Riesch, R., Schlupp, I., \& Plath, R. (2006). Influence of Male Competition on Male Mating Behaviour in the Cave Molly, Poecilia mexicana. Journal of Ethology, 24, 27-31. http://dx.doi.org/10.1007/s10164-005-0156-4

Rodríguez-Luna, E. (1998). Ecología \& conducta de primates. In M. Martínez-Gómez, \& J. Velázquez-Moctezuma (Eds.), Bases neurobiológicas \& ecológicas de la Conducta (pp. 63-89). Tlaxcala, México: UAT, AM, UV, UNAM.

Rodríguez-Luna, E., García-Orduña, F., \& Canales-Espinosa, D. (1993). Translocación del mono aullador (Alouatta palliata): Una alternativa conservacionista. In A. Estrada, E. Rodríguez-Luna, R. López-Wilchis, \& R. Coates-Estrada (Eds.), Estudios primatológicos en México (Vol. 1, pp. 129-178). Xalapa: Biblioteca Universidad Veracruzana.

Rushen, J. (1972). Offense and Defence and the Assessment of Fighting Ability by Domestic Pigs. In D. S. Lehrman, R. A. Hinde, \& E. Shaw (Eds.), Advances in the Study of Behavior (pp. 375-398). New York: Academic Press.

Serio-Silva, J. (2000). Personal Communication.

Snowdon, C. (1991). Naturalistic Environments and Psychological Well-Being. In M. A. Novak, \& A. J. Petto (Eds.), Through the Looking Glass: Issues of Psychological Well-Being in Captive Nonhuman Primates (pp. 103-115). Washington DC: American Psychological Association.

Stenberg, M., \& Persson, A. (2005). The Effects of Spatial Food Distribution and Group Size on Foraging Behaviour in a 
Benthic Fish. Behavioural Processes, 70, 41-50. http://dx.doi.org/10.1016/j.beproc.2005.04.003

Takahashi, A., Sato, K., Nishikawa, J., Watanuki, Y., \& Naito, Y. (2004). Synchronous Diving Behavior of Adélie Penguins. Journal of Ethology, 22, 5-11. http://dx.doi.org/10.1007/s10164-003-0111-1

Tanaka, K., Mori, A., \& Hasegawa, M. (2001). Apparent Decoupling of Prey Recognition Ability with Prey Availability in an Insular Snake Population. Journal of Ethology, 19, 27-32. http://dx.doi.org/10.1007/s101640170014

Taru, M., Kanda, T., \& Sunobe, T. (2002). Alternative Mating Tactics of the Gobiid Fish Bathygobius fuscus. Journal of Ethology, 20, 9-12. http://dx.doi.org/10.1007/s10164-002-0047-X

Tinbergen, N. (1981). El Estudio del Instinto. México: Siglo XXI.

Torres, C. (2005). Análisis de las interacciones espacio-temporales que regulan la funcionalidad del comportamiento bajo reforzamiento contingente \& no contingente. Unpublished Doctoral Thesis, Guadalajara: Universidad de GuadalajaraMéxico.

United States Departament of Agriculture (USDA) (2010). Aninal Welfare Act: Title 9, Chapter 1, Part 3, Supart D, Section 3.81.

http://www.ecfr.gov/cgi-bin/text-idx?c=ecfr\&SID=cfa35ebd192cd672201e7d9bae14c7f6\&rgn=div8\&view=text\&node=9: 1.0.1.1.3.4.28.7\&idno $=9$

Vicente, L. A., \& Paulo, O. (1989). Behavioral and Morphological Adaptations of the Lizard Lacereta lepida to Particular Environmental Constraints. In R. J. Blanchard, P. F. Brain, D. C. Blanchard, \& S. Parmigiani (Eds.), Ethoexperimental Approaches to the Study of Behaviour (pp. 640-643). Dordrecht, Netherlands: Kluwer Academic Publishers.

Wemelsfelder, F. (1990). Boredom and Laboratory Animal Welfare. The Experimental Animal in Biomedical Research, 1, 243-272.

Yabuta, S. (2000). Behaviors in Agonistic Interaction of the Butterflyfish (Chaetodon lunulatus). Journal of Ethology, 18, 11-15. http://dx.doi.org/10.1007/s101640070018

Zipser, B., Kaiser, S., \& Sachser, N. (2013). Dimensions of Animal Personalities in Guinea Pigs. Ethology, 119, $970-982$. 
Scientific Research Publishing (SCIRP) is one of the largest Open Access journal publishers. It is currently publishing more than 200 open access, online, peer-reviewed journals covering a wide range of academic disciplines. SCIRP serves the worldwide academic communities and contributes to the progress and application of science with its publication.

Other selected journals from SCIRP are listed as below. Submit your manuscript to us via either submit@scirp.org or Online Submission Portal.
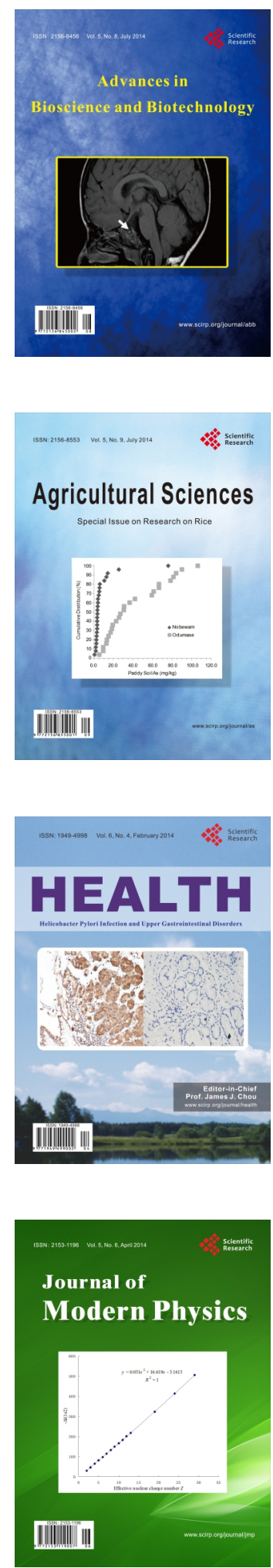
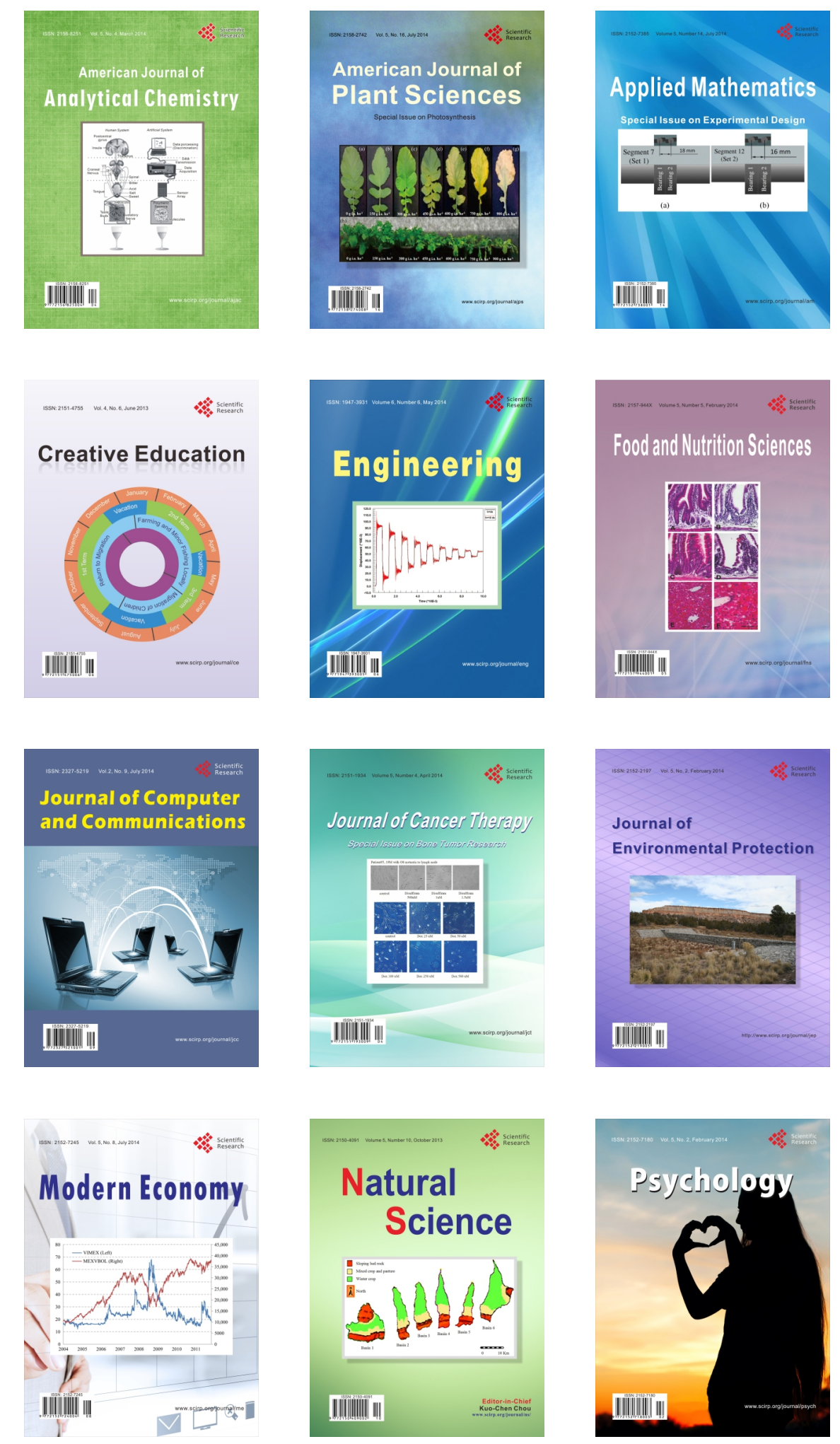